\title{
Reduction of Photosynthetically \\ Active Radiation under \\ Extreme Stratospheric Aerosol Loads
}

\author{
Siegfried A. W. Gersti
}

Andrew Zardecki

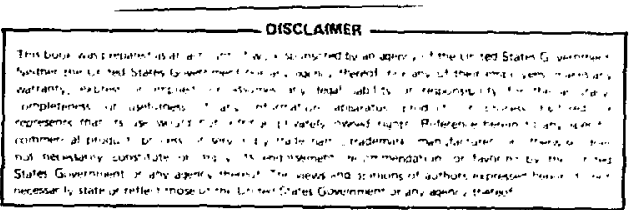

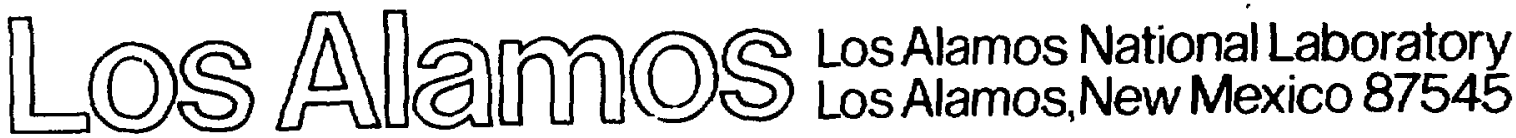


REDUCTIUN OF PHOTOSYNTHETICALLY ACTIVE RADIATION

UNDER EXTREME STRATOSPHERIC AEROSOL LOADS

by

Siegfried A. W. Gerst1 and Andrew Zardecki

\begin{abstract}
The recently published hypothesis that the CretaceousTertiary extinctions might be caused by an obstruction of sunlight is tested by model calculations. First we compute the total mass of stratospheric aerosols under normal atmospheric conditions for four different (measured) aerosol size distributions and vertical profiles. For comparison, the stratospheric dust masses after four volcanic oruptions are also evaluated. Detailed solar radiative transfer calculations are then performed for artificially increased aerosol amounts until the postulated darkness scenario is obtained. Thus we find that a total stratospheric aerosol mass between 1 and 4 times $10^{16} \mathrm{~g}$ is sufficient to reduce photosynthesis to $10^{-3}$ of normal. We also infer from this result that the impact of a $0.4-$ to 3-ka-d:ameter asteroid or a close encounter with a Halley-size comet may deposit that amount of particulates into the stratosphere. The darkness scenario of Alvarez et al. is thus shown to be a possible extinction mechanism, even with smaller size asteroids or comets than previously estimated.
\end{abstract}

\title{
I. INTRODUCTION
}

About one year ago Luis and Walter Alvarez, Frank Asaro, and Helen Michel put forth the hypothesis ${ }^{1}$ that the Cretaceous-Tertiary (C-T) extinctions (sudden disappearance of dinosaurs and other reptiles about 65 million years ago) might have been caused by the consequences of a large meteorite (asteroid) impacting on Earth. Such an impact would produce a global dust layer that would stay aloft in the stratosphere for several years and thus suppress photosynthesis 
to a large extent, which would explain the major features of the extinctions. The physical basis for this hypothesis was provided by the discovery of an apparently worldwide marine sediment layer that shows an anomalously high abundance of iridium most likely originating from an extraterrestrial source. This iridium anomaly has only recently been located in a terrestrial deposit by a group of Los Alamos National Laboratory researchers ${ }^{2}$ in a drill core taken in Northern New Mexico.

The Alvarez/Asaro/Michel hypothesis is being studied and tested by many researchers throughout the country. In particular, the impact mechanics and possible climate consequences have been modeled with some success. Severa! independent arguments have been applied to estimate the size of the asteroid, which Alvarez et al. place at about $10 \pm 4 \mathrm{~km}$ in diameter. In this report we attempt to estimate a lower limit of the asteroid's mass from solar radiative transfer calculations, assuming the presence of various amounts of dust in the stratosphere that we scale up from measured stratospheric aerosol distributions of volcanic origin. We are also discussing a new hypothesis, which postulates that the required aerosol mass could have been deposited in the stratosphert when the Earth, nearly colliding with a comet, swept through the comet's coma and tail (a grazing comet).

During the last year, we have established an advanced computational rapability for atmospheric solar radiative transfer calculations in the context if an environmental research project, ${ }^{3,4}$ where the biologically effective ioia: irradiance at ground level was computed for clear and polluted atmosphers. Potential effects on plant life as a consequence of reduced biologically effective solar irradiance were also studied. We now apply this computationa? system and its data base to calculate the photosynthetically active radiation (PAR) that reaches the ground under different stratospheric pollution scenarios. We can thus model the assumed extreme obstruction of sunlight necessary to reduce photosynthesis by several orders of magnitude with resulting extinction. In addition, we can compute the total mass of the stratospheric ijsi required to achieve an assumed PAR reduction. Using published data on impact mechanics, we can then give a lower limit estimate for the mass and size of the impacting asteroid. 
A quantitative description of atmospheric pollution and its optical properties is usually based on the assumption of a polydispersion of spherica! aerosol particles, ${ }^{5}$ which are allowed to vary in number density (particles/ $/ \mathrm{cm}^{3}$ ) with varying altitude $R$ (vertical profile). The particles are also allowed to vary in size (radius $r$, measured in $\omega$ ) according to a size distribution function $n(r)$ such that $n(r) d r$ gives the number of particles with radii between $r$ and $r+d r$. The complete description of such an atmospheric polydispersion of aerosol particles can therefore be given by an altitude-dependent distribution funct: ion $n(r, R) d r$, which gives the number of particles per $\mathrm{cm}^{3}$ volune with radii between $r$ and $r+d r$ at altitude $R$. If each particle is assumed spherical in shape, then its mass is given by $\frac{4 \pi}{3} r^{3} \rho_{p}$, where $\rho_{p}$ is the specific gravity of the aerosol particle. The vertical mass distribution of such an atmospheric polydispersion is then given by

$$
d M(r, R)=\frac{4 \pi}{3} r^{3} \rho_{p} \cdot n(r, R) d r,
$$

so that the total mass of all aerosol particles per $\mathrm{cm}^{3}$ at altitude $R$ is then computed as an integral over all aerosol sizes:

$$
M(R)=\frac{4 \pi}{3} \rho_{p} \int_{0}^{\infty} r^{3} n(r, R) d r
$$

Assuming a uniform horizontal distribution of these aerosols over the entire globe, we can then integrate Eq. (2) over the entire voluse of the stratosphere to obtain the total mass of stratospheric aerosols.

$$
M=\int_{R_{1}}^{R_{2}} M(R) \cdot 4 \pi R^{2} d R,
$$


where the $R_{2,1}$ indicate the upper and lower boundaries of the stratosphere (assumed to be a spherical shell) measured from the Earth's center. Assuning the same distribution of aerosol sizes at all altitudes in the stratosphere, we can rewrite the altitude-dependent distribution function $n(r, R)$ as the product of a vertical profile $N(R)$ and a size distribution function $n(r)$,

$$
n(r, R)=N(R) \cdot n(r),
$$

so that $N(R)$ gives the total number of aerosol particles (of all sizes) per $\mathrm{cm}^{3}$ at altitude $R$, whereas $n(r)$ is the size distribution function that is normalized to one,

$$
\int_{0}^{\infty} n(r) d r=1 .
$$

Both the vertical aerosol profile $\mathcal{N}(R)$ and the normalized size distribution funciion $n(r)$ have been measured for several stratospheric pollution scenarios and many different aerosol characteristics, and representative data are readily available. 5,6 Inserting Egs. (2) and (4) into Eq. (3) gives the desired expression for the total mass of stratospheric aerosols:

$$
M=\int_{R_{1}}^{R_{2}} \frac{4 \pi}{3} \rho_{p} \int_{0}^{\infty} r^{3} N(R) n(r) d r \cdot 4 \pi R^{2} d R=\rho_{p} \cdot N_{0} \cdot V_{p}
$$

with

$$
N_{0}=4 \pi \int_{R_{1}}^{R_{2}} N(R) R^{2} d R
$$

= Total number of aerosol particles in the entire stratosphere, 
and

$$
\begin{aligned}
V_{p} & =\frac{4 \pi}{3} \int_{0}^{\infty} r^{3} n(r) d r \\
& =\text { Volume occupied by a median-size aerosol particle. }
\end{aligned}
$$

The quantities defined by Eqs. (6) through (8) will be evaluated numerically in the next section for four different stratospheric aerosol models that differ from each other by their specific aerosol characteristics (size distribution, absorption, and scattering coefficients) and vertical profiles.

\section{OPTICAL DATA FOR FOUR STRATOSPHERICAL AEROSOL MODELS}

We used for our radiative transfer calculations the complete set of optical data for atmospheric aerosols recently issued by Shettle and Fenn ${ }^{6}$ of the Air Force Geophysics Laboratory (AFGL). Tt. se data are based on a long history of measurements and have been verified against laboratory and satellite data. All necessary optical parameters (scattering and absorption coefficients, vertical profiles and size distributions of tropospheric and stratospheric aerosols, scattering phase functions, etc.) to perform solar radiative transfer calculations in realistic model atmospheres are taken from this AFGL data base in the spectral region of interest $(0.35$ to $0.75 \mu \mathrm{m})$. In addition to several tropospheric aerosol models, the AFGL data describe four specific stratospheric aerosol models that are our main interest:

$$
\begin{aligned}
& \text { BS }=\text { Background Stratosphere, } \\
& \text { MV = Moderate Volcanic, } \\
& \text { HV }=\text { High Volcanic, } \\
& \text { EV = Extreme Volcanic. }
\end{aligned}
$$

Table I lists the vertical distribution of the aerosol number density $N(R)$ (the vertical profile) for all four stratospheric aerosol models from 10- to 30-k altitude. These data from Table I were used to evaluate $n_{0}$ from Eq. (7).

Three different aerosol size distributions $n(r)$ are used in conjunction with the above stratospheric aerosol models: 


$$
\begin{aligned}
& \text { BS }=\text { Background Stratosphere, } 75 \% \mathrm{H}_{2} \mathrm{SO}_{4}, \\
& \text { FV }=\text { Fresh Volcanic, } \\
& \text { AV }=\text { Aged Volcanic. }
\end{aligned}
$$

All three distributions can be described analytically by a modified gamma distribution function

$$
n(r)=a r^{\alpha} \exp \left(-b r^{\gamma}\right), \text { for } 0 \leq r \leq \infty
$$

The four parameters $a, \alpha, \gamma, b$, which fully describe the polydispersions, are listed in Table II. The maximum of the distribution function, Eq. (9), occurs at $r=r_{c}$ with

$$
r_{c}=\left(\frac{a}{b \cdot \gamma}\right)^{1 / \gamma},
$$

and has a value of

$$
n\left(r_{c}\right)=\operatorname{ar}_{c}^{\alpha} \exp (-\alpha / \gamma)
$$

The mode radius is $r_{c}$, and $r_{c}$ gives the most frequent radius encountered in the polydispersion, whereas $n\left(r_{c}\right)$ gives an indication of how narrow or broad peaked the distribution function is. Both paraneters are also listed in Table II. When Eq. (9) is inserted into Eq. (8), the integral over the size distribution function can be evaluated analytically so that

$$
v_{p}=\frac{4 \pi}{3} \frac{a}{\gamma} b^{-\frac{\alpha+4}{\gamma}} \Gamma\left(\frac{\alpha+4}{\gamma}\right)
$$

Values of $v_{p}$ for the three specific size distributions under consideration are given in the last colunn of Table II. Comparing the last three colums in Table II, we may sumarize that the aged volcanic distribution model represents the finest grain aerosol particles $\left(r_{c}=0.016 \mathrm{~m}\right)$, whereas the fresh volcanic model describes much larger $\left(r_{c}=0.063 \mathrm{~m}\right)$ and heavier particles $\left(v_{p}^{F V} \approx 64 v_{p}^{A V}\right)$ 
TABLE I

VERTICAL PROFILES OF AEROSOL NUMBER DENSITY FOR FOUR STRATOSPHERIC AEROSOL MODELS

Aerosol Number Density, N(R) (particles $/ \mathrm{cm}^{3}$ )

\begin{tabular}{ccccc}
$\begin{array}{c}\text { Height } \\
(\mathrm{km})\end{array}$ & $\begin{array}{c}\text { Background } \\
\text { Stratospheric }\end{array}$ & $\begin{array}{c}\text { Moderate } \\
\text { Volcanic }\end{array}$ & $\begin{array}{c}\text { High } \\
\text { Volcanic }\end{array}$ & $\begin{array}{c}\text { Extreme } \\
\text { Volcanic }\end{array}$ \\
\hline 10.0 & $1.04 \mathrm{E}+01$ & $2.05 \mathrm{E}+01$ & $1.33 \mathrm{E}+00$ & $1.13 \mathrm{E}+00$ \\
11.0 & $7.27 \mathrm{E}+00$ & $2.34 \mathrm{E}+01$ & $1.29 \mathrm{E}+00$ & $1.29 \mathrm{E}+00$ \\
12.0 & $5.83 \mathrm{E}+00$ & $2.72 \mathrm{E}+01$ & $1.50 \mathrm{E}+00$ & $1.50 \mathrm{E}+00$ \\
13.0 & $4.70 \mathrm{E}+00$ & $3.11 \mathrm{E}+01$ & $1.72 \mathrm{E}+00$ & $1.72 \mathrm{E}+00$ \\
14.0 & $4.03 \mathrm{E}+00$ & $3.21 \mathrm{E}+01$ & $2.21 \mathrm{E}+00$ & $2.21 \mathrm{E}+00$ \\
15.0 & $3.59 \mathrm{E}+00$ & $3.24 \mathrm{E}+01$ & $3.21 \mathrm{E}+00$ & $3.21 \mathrm{E}+00$ \\
16.0 & $3.47 \mathrm{E}+00$ & $3.04 \mathrm{E}+01$ & $4.96 \mathrm{E}+00$ & $4.96 \mathrm{E}+00$ \\
17.0 & $3.86 \mathrm{E}+00$ & $2.73 \mathrm{E}+01$ & $7.35 \mathrm{E}+00$ & $7.78 \mathrm{E}+00$ \\
18.0 & $4.73 \mathrm{E}+00$ & $2.33 \mathrm{E}+01$ & $9.32 \mathrm{E}+00$ & $1.42 \mathrm{E}+01$ \\
19.0 & $5.29 \mathrm{E}+00$ & $1.90 \mathrm{E}+01$ & $9.38 \mathrm{E}+00$ & $2.97 \mathrm{E}+01$ \\
20.0 & $5.36 \mathrm{E}+00$ & $1.50 \mathrm{E}+01$ & $7.17 \mathrm{E}+00$ & $6.13 \mathrm{E}+01$ \\
21.0 & $4.57 \mathrm{E}+00$ & $1.21 \mathrm{E}+01$ & $4.35 \mathrm{E}+00$ & $3.37 \mathrm{E}+01$ \\
22.0 & $3.82 \mathrm{E}+00$ & $9.54 \mathrm{E}+00$ & $2.76 \mathrm{E}+00$ & $3.74 \mathrm{E}+00$ \\
23.0 & $2.73 \mathrm{E}+00$ & $7.32 \mathrm{E}+00$ & $1.47 \mathrm{E}+00$ & $1.47 \mathrm{E}+00$ \\
24.0 & $1.80 \mathrm{E}+00$ & $5.71 \mathrm{E}+00$ & $7.84 \mathrm{E}-01$ & $7.84 \mathrm{E}-01$ \\
25.0 & $1.19 \mathrm{E}+00$ & $4.55 \mathrm{E}+0 \mathrm{C}$ & $4.75 \mathrm{E}-01$ & $4.75 \mathrm{E}-01$ \\
26.0 & $8.19 \mathrm{E}-01$ & $3.55 \mathrm{E}+00$ & $2.73 \mathrm{E}-01$ & $2.73 \mathrm{E}-01$ \\
27.0 & $6.16 \mathrm{E}-01$ & $2.78 \mathrm{E}+00$ & $1.78 \mathrm{E}-01$ & $1.78 \mathrm{E}-01$ \\
28.0 & $4.71 \mathrm{E}-01$ & $2.33 \mathrm{E}+00$ & $1.29 \mathrm{E}-01$ & $1.29 \mathrm{E}-01$ \\
29.0 & $3.74 \mathrm{E}-01$ & $1.38 \mathrm{E}+00$ & $7.60 \mathrm{E}-02$ & $7.60 \mathrm{E}-02$ \\
30.0 & $3.02 \mathrm{E}-01$ & $8.43 \mathrm{E}-01$ & $8.43 \mathrm{E}-01$ & $8.43 \mathrm{E}-01$
\end{tabular}

TABLE. II

PARAMETERS OF AEROSOL SIZE DISTRIBUTIONS CONSIDERED

\begin{tabular}{lccccccc}
$\begin{array}{l}\text { Stratospheric } \\
\text { Aerosol Model }\end{array}$ & $\begin{array}{c}\mathrm{a} \\
(\mu \mathrm{m})^{-2}\end{array}$ & $(1)$ & $(1)$ & $\begin{array}{c}\gamma \\
(\mu \mathrm{m})^{-\gamma}\end{array}$ & $\begin{array}{c}\mathbf{r}_{\mathrm{c}} \\
(\mu \mathrm{m})\end{array}$ & $\begin{array}{c}n\left(\mathrm{r}_{\mathrm{c}}\right) \\
(\mu \mathrm{m})^{-1}\end{array}$ & $\begin{array}{c}\mathrm{V}_{\mathrm{p}} \\
\left(10^{-14} \mathrm{~cm}^{3}\right)\end{array}$ \\
\hline Backgr. Strat. (BS) & 324.0 & 1 & 1 & 18 & 0.056 & 6.62 & 1.73 \\
Aged Volcanic (AV) & 5461.3 & 1 & 0.5 & 16 & 0.016 & 11.5 & 1.51 \\
Fresh Volcanic (FV) & 341.3 & 1 & 0.5 & 8 & 0.063 & 3.06 & 96.6
\end{tabular}


The total mass of all aerosols in the stratosphere, Eq. (6), can now be evaluated for all four models with the data from Tables $I$ and II. In all cases, we chose the value of $3 \mathrm{~g} / \mathrm{cm}^{3}$ as a typical specific gravity $\rho_{p}$ for the aerosol particles. Our results are given in Table III. It should be noted that the fresh volcanic size distribution is assigned to both the high (HV) and extreme volcanic (EV) models, whereas the fine-grain aged size distribution is assigned only to the moderate volcanic (MV) model. These assignments are an integral part of the data base described in Ref. 6 .

TARLE II I

TOTAL NUMBER AND MASS OF STRATOSPHERIC AEROSOLS FOR

FOUR COMPUTER MODELS AND FOUR VOLCANIC ERUPTIONS

\begin{tabular}{|c|c|c|}
\hline $\begin{array}{l}\text { Stratospheric } \\
\text { Aerosols }\end{array}$ & $\begin{array}{c}N \times 10^{25} \\
\text { (Particles) }\end{array}$ & $M$ for $\rho_{p_{(g)}}=3 \mathrm{~g} / \mathrm{cm}^{3}$ \\
\hline BS Model & $75 \% \mathrm{H}_{2} \mathrm{SO}_{4}$ droplets & $1.9 \times 10^{12}$ \\
\hline MV Model & Aged Volcanic & $7.7 \times 10^{12}$ \\
\hline HV Model & Fresh Volcanic & $9.0 \times 10^{13}$ \\
\hline EV Model & Fresh Volcanic & $2.6 \times 10^{14}$ \\
\hline St. Helens (1980) & Vol. of $2.7 / 600 \mathrm{~km}^{3}$ & $1.3 \times 10^{13}$ \\
\hline Agung (1963) & Vol. of $9 \times 10^{-3} \mathrm{~km}^{3}$ & $2.7 \times 10^{13}$ \\
\hline Katmai (1912) & Vol. of $1.34 \times 10^{-2} \mathrm{~km}^{3}$ & $4.0 \times 10^{13}$ \\
\hline Krakatoa (1883) & Vol. of $3.0 \times 10^{-2} \mathrm{~km}^{3}$ & $9.0 \times 10^{13}$ \\
\hline
\end{tabular}

For completeness we reproduce (Figs. 1 and 2) the wavelength dependency of typical optical data as used from the AFGL data base. Figure 1 shows the spectral variation of the extinction coefficients for the three stratospheric aerosol types as described in lable II, whereas in Fig. 2 their single scattering albedo is plotted. Because we will limit our calculations to the visible wavelength region $(0.35$ to $0.75 \mathrm{\mu m})$, we nay characterize (Fig. 2) the Eresh volcanic aerosols as more absorbing than the moderate volcanic type, whereas the background stratospheric model is almost exclusively scattering. These 
characteristics are further underlined by the specific values of $r_{c}$ and $v_{p}$ in Table II and the fact that a $75 \%$ solution of sulfuric acid in water has been assumed for the BS model. ${ }^{6}$

Fig. 1 .

Wavelength dependence of the extinction coefficient for three different stratospheric aerosol types. From Ref. 6.

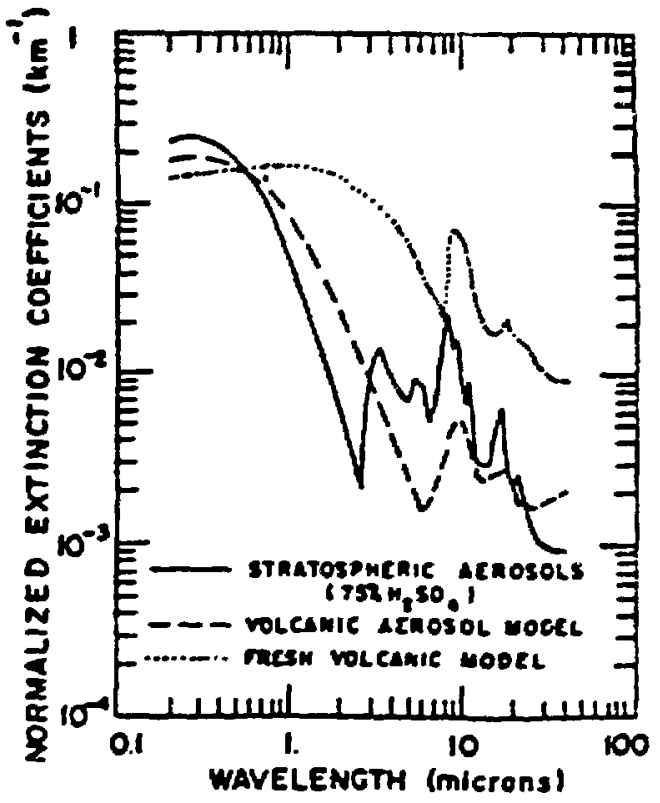

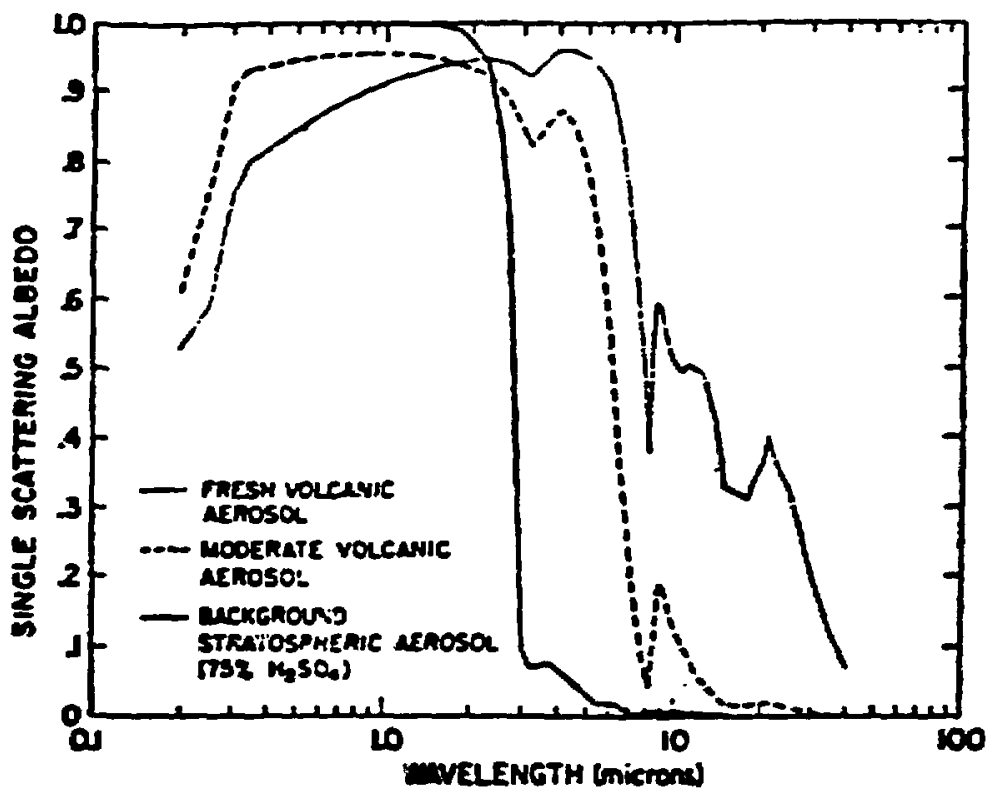

Fig. 2.

Wavelength dependence of the single scattering albedo for three different stratospheric aerosol types. From Kef. 6. 
To develop some feeling for the magnitude of the total masses of stratospheric aerosols as calculated in the last section and listed in Table III, we include in Table III the stratospheric aerosol masses as estimated for the four largest volcanic events recorded on Earth over the last 100 years. The volume of ejecta that reached the stratosphere in the Agung, Katmai, and Krakatoa eruptions has been derived by Deirmendjian from recorded measurements of optical phenomena. ${ }^{7}$ In particular, the increased optical thicknesses as derived from reduced transmissivities of sunlight were used to estimate the additional stratospheric turbidity created by these eruptions. Deirmendjian consistently derives a ratio of 1:600 for stratospheric dust to total mass of ejecta for the three eruptions, which leads him to the volumina listed in Table IIJ. The volume of $2.7 \mathrm{~km}^{3}$ of estimated total ejecta for the most recent Mt. St. Helens eruption is taken from $R$. and $B$. Decker. ${ }^{8}$ Using the $1: 600$ ratio and $\rho_{p}=3 \mathrm{~g} / \mathrm{cm}^{3}$ leads us to the estimate of $1.3 \times 10^{13} \mathrm{~g}$ of aerosol mass injected into the stratosphere by the $\mathrm{St}$. Helens eruption.

The largest volcanic event in recent history, the Krakatoa eruption in 1883, deserves some more attention because the Krakatoa Connittee of the Royal Society estimated in its report ${ }^{9}$ "the initial mass of material contained in the airborne dust to be equivalent to some $4 \mathrm{~km}^{3}$ of solid matter expelled from the volcano," out of a total of $18 \mathrm{~km}^{3}$ for all the ejecta. This ratio of 4:18 for dust to total ejecta is in conflict with Deimendjian's ratio of $1: 600$. Recognizing this discrepancy, Deirmendjian writes: ${ }^{7}$ "We note in passing that if we accept the Krakatoa Conmittee's own estimate of $4 \mathrm{~km}^{3}$ of material injected into the stratosphere as dust,...we arrive at...a dust veil with the fantastic optical thickness of $\tau_{D}=80$ over the entire intertropical zone!" He concludes then: "Thus the total mass of either the Katmai or the Krakatoa atmospheric dust could hardly bave exceeded $10^{-8}$ of that of the entire atmosphere $\left(5.14 \times 10^{21} \mathrm{~g}\right)$ or the large portions thereof that were affected, whereas the corresponding total optical thickness was little more than doubled with respect to that found under cloudless and very clear conditions away frcs urban pollution centers." Our detailed radiative transfer calculations, described in the next section, confirm Deirmendjian's conclusion. We accept therefore his estimates of airborne dust masses with long residence iines for the Krakatua, Katmai, and Agung events. 
The comparison of these stratospheric aerosol masses with the nass of the entire atmosphere appears quite instructive. We might add also, for comparison, that the total air ass in the stratosphere between $10-$ and $30-k$ height, where we assume our model aerosols to reside, is $1.7 \times 10^{21} \mathrm{~g}$ of which the Krakatoa dust mass is only a very small fraction, namely $5.3 \times 10^{-8}$.

\section{v. SOLAR RADIATIVE TRANSFER CALCUI.ATIONS}

Having defined our stratospheric aerosol models, we intend to compute the spectral distribution of the solar irradiance reaching the ground $(z=0)$ :

$$
F(z=0, \lambda)=\int_{0}^{1} \psi(z=0, \lambda, \mu) \cdot \mu d \mu,
$$

where $\psi(z, \lambda, \mu)$ is the radiance at height $z$, which we obtain as the solution of the radiative transfer equation. The discrete-ordinates computer code ONETRAN 10 is applied for the numerical solution, which includes all orders of scattering and allows highly anisotropic phase functions to be considered. An $\mathrm{S}_{40}$ approximation was employed that resolves the angular distribution of the radiance with $\mathbf{4 0}$ discrete directions. The entire visible region of the solsr spectrum was divided into 42 wavelength groups between 0.35 and $0.75 \mathrm{~mm}$, and the atmosphere was described with 31 horizontal zones up to $70-\mathrm{km}$ height. In addition to the stratospheric aerosols already described in the previous section, we considered standard atmospheric conditions (midlatitude sumer) above and below the stratosphere including molecular absorption (mainly ozone), Rayleigh scattering, and a constant distribution of rural-type aerosols in the tropospheric boundary layer corresponding to $5-\mathrm{km}$ visual range at the surface. The addition of this constant aerosol layer in the troposphere should simulate the continuous settling of heavier stratospheric aerosol particles. We also assuned a constant $80 \%$ relative humidity in this tropospheric boundary layer up to 2-ke height.

\footnotetext{
In Sec. $V$, we used the symbol $R$ to denote the altitude measured from the center of the Earth. Here $z$ is the height above sea level.
} 
Because we are interested in effects of reduced solar irradiance on plants at ground level, we extracted from the spectral distribution of the solar irradiance the part that is active in the process of photosynthesis. This photosynthetically active radiation (PAR) is defined in photobiology as 11,12

$$
\operatorname{PAR}=\int_{\lambda_{1}}^{\lambda_{2}} \mathrm{E}(\lambda) \mathrm{F}(z=0, \lambda) \mathrm{d} \lambda
$$

where $\lambda_{1,2}$ are the wavelengths for which the action spectrum $E(\lambda)$, for photosynthesis of a given plant, tends to zero. For example in Ref. $12, n_{1}=0.35 \mu \mathrm{m}$ and $\lambda_{2}=0.75 \mu \mathrm{m}$ for all crop plants. PAR may also be described as the biologically effective irradiance (BEI) for that plant. Recentiy we performed computations of PAR for four different agriculturally important plants (corn, wheat, soybeans, and green algae) and evaluated quantitatively the effects of increased tropospheric aerosol loads on PAR. ${ }^{3,4}$ Considerable reductions of PAR have been found as aerosol concentrations in the 2-km-high tropospheric boundary layer are increased. Typically, the PAR for corn is reduced by $33 \%$ (53\%) when the air pollution by rural (urban) aerosols increases so that the surface visual range of nominally $300 \mathrm{~km}$ for clear air is reduced to $5 \mathrm{~km}$. The computed PAR reductions for the other three plants agree with those of wheat within $10 \%$, which indicates that PAR according to Eq. (14) is insensitive to the choice of the four plants' action spectra $\mathrm{E}(\lambda)$. In fact, the measured photosynthesis action spectra for 21 species are very similar to each other as shown in Fig. 3, which is reproduced from the work of $\mathrm{McCree}^{12}$ for completeness.

We report here results of PAR calculations for a scenario where only the toical amount of the stratospheric aerosols at heights between 10 and $30 \mathrm{~km}$, as described in Sec. III, are varied. The composition of the rest of the atmosphere up to $70-\mathrm{km}$ altitude and down to ground level remains unchanged. We chose this scenario because we are trying to identify situations that can lead to PAR reductions maintained over time periods of up to several years, but at least one growing season. Tropospheric rural-type aerosols are also expected to $h$ present in such situations but not at an easily identifiable constant 
Fig. 3.

Spectral quantum yields for photosynthesis of 21 species. From Ref. 12.

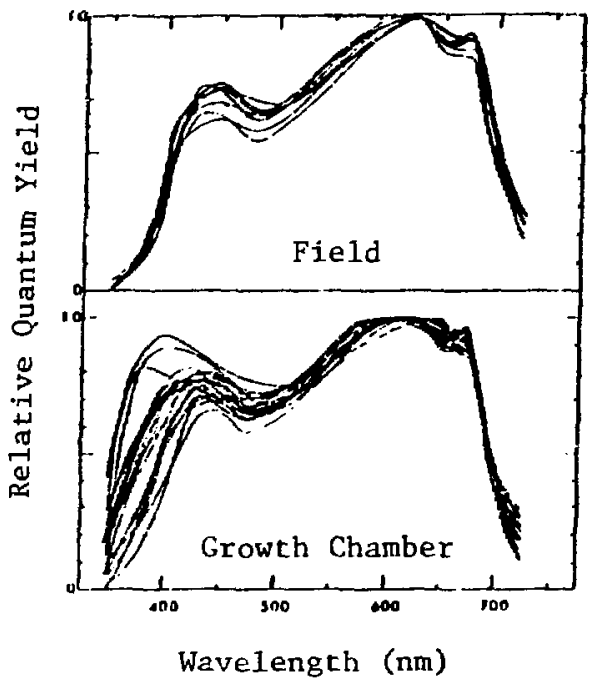

concentration due to frequent rain-out and continuous settling-out of heavier stratospheric aerosol particles.

In Fig. 4 we give the calculated reductions of PAR versus increased total amounts of stratospheric aerosols for the four different aerosol models described in Sect. III. The PAR for a normal stratospheric aerosol load, (PAR) 0 as computed for the background stratospheric aerosol model with a total aerosol mass of $1.9 \times 10^{12} \mathrm{~g}$, is used as the reference value and is thus set to 1.0 in Fig. 4. As a representative photosynthesis action spectrum we chose that of corn, ${ }^{12}$ and all data in Fig. 4 are for an effective solar zenith angle of $52^{\circ}$, which is a reasonable global average $u_{\varsigma}$ in many climatology calculations. 13 Resilts for other solar zenith angles (40 to 60 degrees) deviate only insignificantly from the $52^{\circ}$ results, especially for the high stratospheric aerosol masses of interest.

After computing PAR for the four aerosol models described in Sec. III, we multiplied their vertical number densities by a series of increasing numbers $m(m>1.0)$ and repeated all four calculations for each $m$. This scaling-up of the stratospheric aerosol amounts was continued up to $\mathrm{m}=10^{5}$. For a total stratospheric aerosol mass of $9 \times 10^{13} \mathrm{~g}$, which corresponds to the estimated airborne dust mass of the Krakatoa eruplion, we obtain thus a PAR reduction between 10 and $25 \%$ for the three volcanic models. For comparison, Bullard 14 cites a $20 \%$ reauction in solar radiation following the eruption of Katmai. 




Fig. 4.

Reduction of photosynthetically active radiation resulting from increased stratospheric aerosols for four different aerosol wodels. 
However, a constant reduction of the photosynthetically active radiation of about $25 \%$ or less during a growing season affects most agricultural crop yields only marginally (if at all) because the photosynthesis rate of most plants (all $C_{3}$ plants) is already saturated at much less (40 to 60\%) than the normal full solar irradiance. 15 In contrast, if we were to take the Krakatoa Comittee's airborne dust estimate of $4 \mathrm{~km}^{3}$ or $1.2 \times 10^{16} \mathrm{~g}$ (with our assumed density of $\left.3 \mathrm{~g} / \mathrm{cm}^{3}\right)$, PAR would be reduced to $3 \%$ of normal, $f$ the EV aerosol model is assumed, or even to $0.03 \%$ if the MV model aerosol characteristics are assumed. Such large reductions in the biologically effective solar irradiance would certainly have been reported even if they had happened only in a small latitude band around the equator. Our results for the scaled-up background stratosphere model give the lowest PAR reductions for a given aerosol mass because the BS aerosol composition is assumed to be a $70 \%$ solution of $\mathrm{H}_{2} \mathrm{SO}_{4}$ in water droplets, 6 which has very little absorpticn in the visible as seen from Fig. 2. The results for the BS model are included in Fig. 1 for completeness; we do not want to exclude a scenario where extensive amounts of water vapor are in the stratosphere.

VI. CORNECTIONS WITH AN ASTEROID OR COMET IMPACT

The mechanism that may have produced the Cretaceous-Tertiary extinctions, as described by Alvarez et al., postulates an asteroid impact that ejected enough dust into the atmosphere to reduce photosynthesis drastically on the entire globe and for an extended period of time. As mentioned by other authors, such a darkness scenario might have been generated also by a collision with a comet or by a super Tunguska event. We will comnent on these hypotheses, which are based on the darkness scenario, in light of the results of our modeling.

From Fig. 4 we can obtain directly the total mass of stratospheric aerosols that is required to reduce PAR to a given fraction of the normal amount. Although it is not clear how much reduction in PAR is required to produce the $C-T$ extinctions, we will assume here that a reduction to $1 / 1000$ of normal is sufficient to initiate the extinction mechanism postulated by the darkness hypothesis, if this darkness persists over at least one full growing season worldwide. With this assumption, Fig. 4 shows that a minimum mass of $10^{16} \mathrm{~g}$ in the stratosphere is sufficient to produce a PAR reduction to $10^{-3} \times(P A R)_{0}$ if the aged volcanic 
aged volcanic aerosol characteristics are assumed. This minimum mass is increased to $4 \times 10^{16} \mathrm{~g}$ if the background stratospheric aerosol model is used. Note that, because of the steep drop of all four curves in Fig. 4 for large aerosol loads, the assumption of $\mathrm{PAR}=10^{-3}(\mathrm{PAR})_{0}$ to be sufficient for the $C-T$ extinctions, is not critical. In fact, an order of magnitude over- or unde:estimation would change the minimum required total stratospheric aeros $n 1$ mass insignificantly, even if an attenuation of sunlight of the order of $10^{-7}$ is assumed, as Alvarez et al. ${ }^{1}$ do. Therefore, in the following discussion, we use

$$
M_{\min .}^{\text {STRAT. }}=1 \times 10^{16} \text { to } 4 \times 10^{16} \mathrm{~g} \text {. }
$$

\section{A. The Minimum-Size Asteroid}

To estimate the minimum size of a single solid asteroid capable of deposiling on impact with Earth 1 to 4 times $10^{i 6} \mathrm{~g}$ of aerosols or dust into the stratosphere, we require additional information on the impact mechanics of such large objects. $O^{\prime}$ Keefe and Ahrens ${ }^{16}$ have recently concluded from studying such impact mechanics that a bolide of mass M striking Earth could deposit ejecta in the stratosphere of total mass between 1 and 100 times the bolide mass; that is,

$$
\alpha=\frac{M^{\text {STRAT. }}}{M^{\text {ASTER. }}}=1 \text { to } 100 .
$$

For completeness, the data from which this estimate is derived are reproduced in Figs, 5 and 6 (from Ref. 16).

Assuming a spherical asteroid with volume $V_{A}=\frac{4 \pi}{3} R_{A}^{3}$ and an average density of $\rho_{A}=3 \mathrm{~g} / \mathrm{cm}^{3}$, we can easily compute with Egs. (15) and (16) the diameter $\mathrm{D}_{\text {min. }}^{\text {ASTER. }}$ of a minimum-size asteroid capable of injecting the aerosol mass Min. into the stratosphere.

(a) We obtain a lower Iimit for $D_{\text {min. }}^{\text {ASTER. }}$ of $0.4 \mathrm{~km}$ if the lowest value from Eg. (15) is taken together with the estimated maximum value of $\alpha=100$ from Eq. (16). 


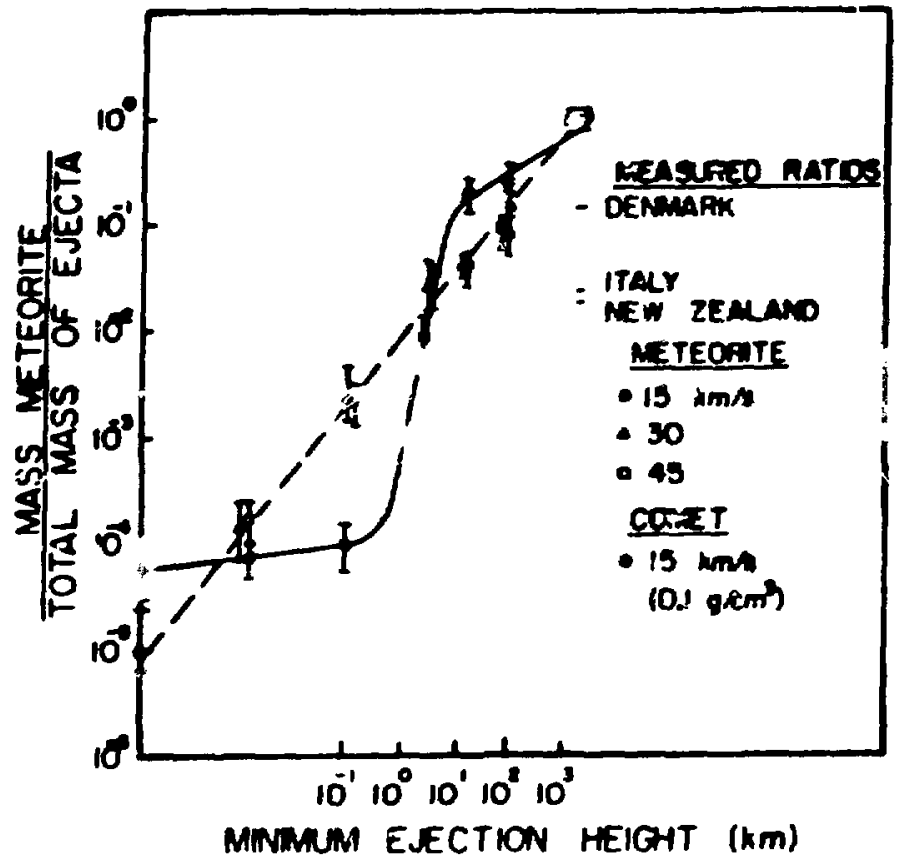

Fig. 5 .

Meteorite mass (extrater restrial material) divided by the total mass of ejecta lofted to at least a given height in the Earth's gravity field for silicate (2.9 $\left.\mathrm{g} / \mathrm{cm}^{3}\right)$ and water $\left(0.1 \mathrm{~g} / \mathrm{cm}^{3}\right)$ objects impacting a silicate earth. From Ref. 16 .

Fig. 6.

Total mass ejected (normalized to impactor mass) versus minimue ejection height in the Earth's gravity field. Impact of silicate $\left(2.9 \mathrm{~g} / \mathrm{cm}^{3}\right)$ and cometary $\left(0.1 \mathrm{~g} / \mathrm{cm}^{3}\right)$ objects onto silicate half-space is assumed. From Ref. 16.

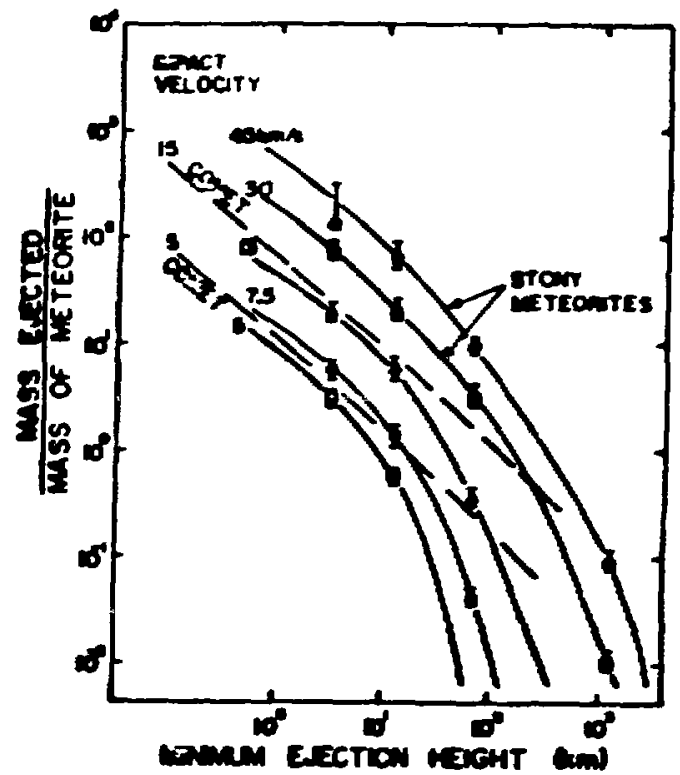


(b) An upper limit for $D_{m i n}^{A S T E R}$. of $2.9 \mathrm{~km}$ is obtained by using the other two extreme values from Eqs. (15) and (16).

Sumarizing, we can write

$$
\mathrm{D}_{\text {min. }}^{\mathrm{ASTER} .}=0.4 \text { to } 2.9 \mathrm{tm}
$$

which is less than the 10- \pm 4-km estimate of Alvarez et al. based on other arguments. However, this difference is no contradiction because $D_{\text {min. }}^{\text {ASTER. gives }}$ only the minimum size of the asteroid required to support the darkness scenario, whereas any larger asteroid would also initiate this extinction mechanism. Our relatively small minimum asteroid size may help to search for the as yet unidentified impact crater of an estimated minimum diameter between 8 and $60 \mathrm{~km}$, using crater scaling as discussed in Ref. 17. It would be highly desirable, of course, to reduce the large spread of a-values to be able to further narrow down the estimated minimum values for the size of the asteroid as well as its impact crater.

\section{B. A Cometary Collision or Close Encounter}

Because of the relatively small mass of stratospheric aerosols required to produce the postulated darkness, mechanisms other than the asteroid impact appear also possible or even likely to explain the deposition of $M_{m i n}^{S T R A T}$ into the stratosphere. The most likely such mechanism appears to us to be a collision or close encounter with a comet. Because most comets are believed to consist of about equal masses of dust and icy constituents, 18-20 it is most likely that most cometary particles would never reach the Earth's surface in the case of a collision with Earth as is believed to have ocrurred on 30 June 1908 over Tunguska, Siberia. ${ }^{21}$ Hence, no impact crater would be produced. In addition, the statistics of observed conets support the assumption of a much higher probability for a comet/Earth collision than for an asteroid impact, 22 especially if the newly estimated values for $M_{\text {min. }}^{S T R A T}$. are considered. We conjecture in the following that even a near miss allows the Earth's atmosphere to pick up enough particulate natter from the comet to produce the darkness scenario. 
Up to 1950, a total of 43 periodically appearing comets were observed to complete at least 2 solar orbits, 20 and Halley's comet alone came within the visual range of Earth on 29 orbits. The average mass of all observed comets has been estimated from photometric measurements to lis between $10^{16}$ and $10^{17} \mathrm{~g}$. For Halley's comet, four additional independent mass deierminations are cited in Ref. 20, which lead to $3 \times 10^{19} \mathrm{~g}$ for this well-studied comet; more recent estimates arrive at about $6 \times 10^{16} \mathrm{~g} \cdot{ }^{26}$ For example, only a fraction of the total estinated mass of Halley's comet need be deposited in the stratosphere to create the postulated darkness scenario. We estimate that a lengthwise sweep of Earth through Halley's comet's $3 \times 10^{7}-\mathrm{km}-10 n_{8}$ tail ${ }^{20}$ could last up to 21 days assuming a relative speed of $16.6 \mathrm{~km} / \mathrm{s}$. This effective difference of the Earth's and comet's speed is possible when a "slow" comet collides with the trailing surface of the Earth. 23 The continuous deposition of fine particulates and gaseous and plasma constituents in the upper atmosphere could provide a reasonable mechanism to create the postulated darkness scenario and produce the observed iridiun anomaly at the $C-T$ boundary without requiring the existence of an impact crater. The underlying assumption is, of course, that the dust-to-gas ratio in the comet's coma and tail is high enough to produce the observed C-T boundary layer after fallout. Both present-day views of comets as dirty snowballs or dust swarms ${ }^{19}$ do not exclude this possibility. The energetic effects of a $10^{18}-g$ comet colliding with Earth have been estimated by Urey, 23 who found that, if all energy were absorbed, it fuuld be sufficient "to throw a mass of $3.24 \times 10^{19} \mathrm{~g}$ in a circle about Earth." From such energy balance considerations alone Urey concluded that "it does seem possible and even probable that a comet collision with the Earth destroyed the dinosaurs and initiated the Tertiary division of geologic time." Kyte et al. 24 favor the super-Tunguska mechanism suggesting "that an object in a nonintersecting orbit broke up into a large number of objects as it passed inside the Roche limit, with a portion of the debris entering new orbits that intersect the Earth's surface." Obviously, detailed modeling calculations of how comets or other objects behave in close proximity to Earth could shed much light on the above hypotheses. A decisive ruling between the asteroid or comet hypotheses might be expected from seasurements of the iridium mixing ratios at the $C-T$ boundary by determining the relative amount of terrestrial material contained in that layer (which must be larger for the asteroid than for the comet impact). 
VII. CONCLUSIONS

Our atmospheric radiative transfer calculations indicate that a total nass of aerosols between 1 and 4 times $10^{16} \mathrm{~g}$ distributed globally over the Earth's stratosphere is sufficient to reduce the photosynthetically active solar radiation at ground level to $1 / 1000$ of normal. An equivalent amount of dust could be deposited into the stratosphere as ejecta from an impacting asteroid between 0.4 and $3 \mathrm{~km}$ in diameter, or as the consequence of an Earth/comet collision or close encounter. The resulting darkness on Earth's surface alone would be sufficient to initiate the Cretaceous-Tertiary extinction mechanisn hypothesized by Alvarez et al. if it persisted for at least one growing season. The superposition of other extinction mechanisms like a heat flash followed by substantial climate modifications, as discussed by Emiliani, ${ }^{25}$ would add to the stress situation in the biosphere. Because our results determine only the minimum required stratospheric aerosol mass to pruduce the darkness scenario, we find no contradiction between the estimate of Alvarez et al. of $10 \pm 4 \mathrm{~km}$ for the asteroid diameter and our minimum-size estimate of 0.4 to $3 \mathrm{~km}$. We extend, however, the nimber of impact craters on Earth that could possibly be related to the $C-T$ event. Even a close encounter with a Halley's-size comet or a sweep through an interstellar cloud becomes a plausible source for the deposition of 1 to 4 times $10^{16} \mathrm{~g}$ of fine-grain particulates into the stratosphere without producing any sizable impact crater.

\section{ACKNOWLEDGMENTS}

We appreciate the full support and interest in this work by George Bell, Jack Barnes, and Johndale Solem of Los Alamos, who consider such spin-offs from our programatic work as important as our day-to-day chores. Our thanks are extended to Walter Huebner, Stirling Colgate, and Arthur Cox for interesting discussions that we view as the life line for such a multifaceted project. Charles Orth, Helen Michel, and John $O^{\prime}$ Keefe provided very helpful criticism and encouragenent for which we are grateful. 


\section{REFERENCES}

1. Luis W. Alvarez, Walter Alvarez, Frank Asaro, and Helen V. Michel, "Extraterrestrial Cause for the Cretaceous-Tertiary Extinction: Experiment and Theory," Lawrence Berkeley Laboratory report LBL-9666 (December 1979). Also Science 208, 1095-1108 (1980).

2. C. J. Orth, J. S. Gilmore, J. D. Knight, C. L. Pillmore, R. H. Tschudy, and J. E. Fassett, "Iridium Anomaly at the Palynological Cretateous-Tertiary Boundary in New Mexico," 1981 Spring Meeting of the Anerican Geophysical Union, Baltimore, May 25-29, 1981. EOS, Vol. 62, No. 17 (1981), p. 438.

3. S.A.W. Gerstl and A. Zardecki, "Solar Irradiance in Clear and Polluted Atmospheres and Potential Effects on Plant Life and Clinate. Mid-Year Progress Report for FY-81 on EPA Project LASLX-A-1, (April 1981)," Los Alamos National Laboratory report LA-8854-SR (June 1981).

4. A. Zardecki and S.A.W. Gerstl, "Calculations of Solar Irradiances in Clear and Polluted Atmospheres and Potential Effects on Plant Life," Los Alamos National Laboratory report (in preparation).

5. D. Deirmendjian, Electromagnetic Scattering on Spherical Polydispersions (American Elsevier Publishing Co., New York, 1969).

6. E. P. Shettle and R. W. Fenn, "Models of the Aerosols of the Lower Atmosphere and Effects of Humidity Variations on the Optical Properties," Air Force Geophysics Laboratory report AFGL-TR-79-0214 (September 1979). Also, AGARD Conference Proceedings No. 183 (1975).

7. D. Deirmendjian, "On Volcanic and Other Particulate Turbidity Anomalies," in Advances in Geophysics, H. E. Landsberg and J. van Mieghas, Eds. (Academic Press, New York and London, 1973) pp. 267-296.

8. R. and B. Decker, "The Eruptions of Mt. St. Helens," Scientific Anerican 244, 52-64 (March 1981).

9. G. J. Symons, Ed., The Eruption of Krakatoa and Subseguent Phenomena, (Krakatoa Committee, Royal Society, London, 1888).

10. T. R. Hill, "ONETRAN: A Discrete Ordinates Finite Element Code for the Solution of the One-Dimensional Multigroup Transport Equation," Los Alamos Scientific Laboratory report LA-5990-MS (June 1975).

11. W. Larcher, Physiological Plant Ecology, 2nd edition (Springer Verlag, Berlin, 1980).

12. K. J. McCree, "The Action Spectrum, Absorptance and Quantun Yield of Photosynthesis in Crop Plants," Agric. Meteor. 9, 191-216 (1971).

13. S. H. Schneider and R. E. Dickinson, "Climate Modeling," Review of Geophysics and Space Physics 12, 447-493 (1974). 
14. F. M. Bullard, Volcanoes of the Earch (University of Texas Press, Aust in and London, $1 9 7 6 \longdiv { \text { , p. } 5 1 4 . }$

15. D. W. Lawlor, "Effects of Water and Heat Stress on Carbon Ketabolism of Plants with $C_{3}$ and $C_{4}$ Photosynthesis," in Stress Physiology in Crop Plants (Wiley Interscience, Hew York, 1979), py. 303-325.

16. J. D. $O^{\prime}$ Keefe and T. J. Ahrens, "Impact Mechanics of the Cretaceous-Tertiary Extinction Bolide," Twelfth Lunar and Planetary Science Conference, March 16-20, 1981. Abstracts compiled by the Lunar and Planetary Institute, Houston, Texas.

17. R. Wolf, A. B. Woodrow, and R.A.F. Grieve, "Meteoritic Material at Four Canadian Impact Craters," Geochimica et Cosmochimica Acta Vol. 44, 1015$1022(1980)$.

18. F. L. Whipple, "Background of Modern Conet Theory," Nature 262, 15-19 (1976).

19. D. W. Hughes, "Are Comets Dirty Snowballs or Dust Swarms?" Nature 270, 558-560 (1977).

20. N. B. Richter, Statistik und Physik der Kometen, (J. A. Barth Verlag Leipzig, 1954).

21. J. C. Brown and D. W. Hughes, "Tunguska's Comet and Non-Thermal ${ }^{14} \mathrm{C}$ Production in the Atnosphere," Nature 268, 512-514 (1977).

22. K. J. Hsü, "Terrestrial Catastrophe Caused by Cosetary Impact at the End of Cretaceous," Nature 285, 201-203 (1980).

23. H. C. Urey, "Cometary Collisions and Geological Periods," Nature 242, 32-33 (1973).

24. F. T. Ky:e, Z. Zhon, and J. T. Watson, "Siderophile-Enriched Sediments from the Cretaceous-Tertiary Boundary," Nature 288, 651-656 (1980).

25. C. Emiliani, "Death and Renovation at the End of the Mesozoic," EOS 61, No. $26,505-506(1980)$.

26. "The International Halley Watch," Report of the Science Working Group, NASA TM 8218I (July 1980). 